\title{
The Impact of Knowledge Management on the Marketing Performance of Small and Medium Enterprises in the State of Kuwait
}

\author{
Abdulmohsen S. Z. Al-Ajami ${ }^{1} \&$ Prof. Marzouq Ayed Al-Qa'eed ${ }^{2}$ \\ ${ }^{1} \mathrm{PhD}$ researcher, Faculty of Business and Finance, the World Islamic Sciences and Education University, Jordan \\ ${ }^{2}$ Professor of Business, Faculty of Business and Finance, the World Islamic Sciences and Education University, \\ Jordan \\ Correspondence: Abdulmohsen S. Z. Al-Ajami, PhD researcher, Faculty of Business and Finance, the World \\ Islamic Sciences and Education University, Jordan
}

Received: April 10, 2020

Accepted: May 12, 2020

Online Published: May 13, 2020

doi:10.5539/mas.v14n6p21

URL: https://doi.org/10.5539/mas.v14n6p21

\begin{abstract}
The study aimed to measure the Impact of Knowledge Management on the Marketing Performance of Small and Medium Enterprises in the State of Kuwait. The population of the study comprised of the owners of small and medium enterprises in the State of Kuwait. An appropriate sample of 150 respondents was used and 124 valid questionnaires were retrieved for analysis.

The study reached an effect of knowledge management has been found on the marketing performance in small and medium projects in the State of Kuwait. This reflects the importance of attention to diversifying the sources of obtaining knowledge from the environment surrounding the project in a manner that can be used to its advantage in order to improve the level of its marketing performance. The study also highlighted that the opinions of the study sample on the impact of knowledge management on the marketing performance in small and medium enterprises in the State of Kuwait do not differ according to their practical experiences and scientific qualifications.
\end{abstract}

Keywords: knowledge, knowledge management, marketing performance, small and medium enterprises

\section{Introduction}

The current era witnesses a huge knowledge revolution in the field of information, where the one who possesses knowledge has the power, competitiveness and creativity, and modern organizations see knowledge as an effective basis for the processes of creativity, innovation and development. Modern organizations continuously strive to achieve efficiency and effectiveness and achieve outstanding performance. For this reason, the organizations are continuously developing their goals and products that satisfy the needs and desires of consumers in the targeted markets. To achieve this, organizations must gain renewable knowledge and create high-value intellectual capital that gives organizations A great and effective competitive situation in light of the knowledge economy. (Waltz, 2003)

Today, small and medium enterprises are among the largest sectors that support the Kuwaiti economy, in terms of the large number of job opportunities that they provide, and distribute them to various sectors of restaurants, retail companies, salons, and others.

It enjoys great support from those in charge of the financial policy in the country, in addition to the establishment of some small projects by some of the businessmen that help them to obtain great returns and quick profits in the short and medium term.

Small projects are among the sectors that have most benefited from government support in the recent period. Perhaps this is reflected in the establishment of the fund for the National Fund for the Care and Development of Small and Medium Enterprises according to Law No. (98 of 2013) with a capital of two billion Kuwaiti dinars, after the establishment of many funds To support these projects, some of which have met with success, while this success has not been written for others, as the beginnings of establishing such funds in Kuwait date back to the 1990s.

The importance of this study lies in achieving an academic scientific benefit in what its results are expected to 
add to the knowledge, and filling the gap in the research literature, as a result of the scarcity of studies on this topic. In addition to the increasing interest in the subject of knowledge management at the level of small and medium enterprises, which enabled them to achieve tangible success in its business. This study will also contribute to achieving a practical benefit that emerges in providing a set of recommendations necessary to improve the level of marketing performance in small and medium enterprises. The determinants of the study are highlighted in its limitations to Small and medium enterprises in Kuwait.

\section{Problem of the study}

Small and medium enterprises do not live in Kuwait in isolation from the world and from international institutions, they are influenced and affected by the variables around them, and therefore they are called to accelerate to benefit from knowledge management in improving the level of marketing performance in a way that is compatible with the developments and challenges of the era, hence the problem of study summarized in answering the following questions:

-What is the impact of knowledge management on improving marketing performance in small and medium enterprises in the State of Kuwait?

- Are there differences in the impact of knowledge management on improving the marketing performance in small and medium enterprises in the State of Kuwait due to (the educational qualification, practical experience) of the owners of small and medium projects?

\section{Literature Review}

\subsection{Knowledge Management}

There are many definitions that define elements of knowledge management. Martins, Heisig, \& Vorbeck (2001, 8), defined knowledge management as a process of encouraging individuals to exchange knowledge between them as it creates the appropriate environment and systems appropriate to knowledge acquisition, organization and sharing throughout the organization.

Little and Ray $(2005)(2002,9)$ defined it as a thriving business generation system and learning environment that would encourage the generation, compilation, use, and reuse of both personal and organizational knowledge in pursuit of a new business value.

As for Nuri (2011, 134), he defined it as "an integrated and interconnected system of values, skills, experiences, competencies and technologies represented by individuals with excellent brains that organizations use as best they can to help in making decisions and achieving the goals of organizations to ensure their survival, growth and continuity by competing in the markets."

Knowledge management can also be defined as "processes of acquiring knowledge, creating knowledge or transferring, storing knowledge, exchanging knowledge, retrieving knowledge and applying knowledge" (Kwakye, 2015,103 Nor and Ologbo,).

In addition, Nicolas (2004) emphasized that knowledge management is an effective process for creating, obtaining, distributing, monitoring and using knowledge, to maintain competitive advantage and achieve organizational goals. (P.23)

Knowledge management also refers to a set of practices and technologies that organizations use to identify, represent, and distribute knowledge, knowledge, expertise, intellectual capital, and other forms of knowledge in order to promote, reuse, and transfer knowledge and science across the organization. The knowledge management framework consists of components such as identification, acquisition, development, dissemination and use of knowledge (Perera \& Ranawaka, 2016).

Knowledge management has witnessed during the recent period a great development in the degree of acceptance and increased interest in it by many organizations in developing countries due to the role of knowledge in business success and the development of societies, and in achieving competitive progress at the level of individuals, groups, organizations and societies, where it is noted that countries and societies rise in areas of progress Civilization and industrial development without possessing natural wealth or geopolitical advantages except that they have the ability to manage knowledge and employ it in investments that stimulate economic growth (Little and Ray, 2005, 9).

The importance of knowledge management emerges through providing many opportunities for organizations to achieve competitive progress by inventing new methods of production and work that contributed to reducing costs and thus increasing profits in developed countries. As for developing countries, especially Arab ones, they suffer from a tremendous lack of capacity due to the deficiency of the educational system In it, and the limited 
use of information systems, which makes it suffer from a widening knowledge gap that separates it from developed countries, and this gap cannot be narrowed unless targeted policies are taken to improve and increase learning opportunities and openness to the world. In addition to the role of knowledge management in creating new production methods, it also enhances performance at work and organizational ability to provide services at the necessary speed so that it can cope with changes in needs in the target market (Hung, et al., 2015, 501).

According to the theory of knowledge, knowledge is an intellectual asset and a source for achieving competitive advantage, as knowledge development and the life cycle of knowledge contribute, knowledge shares, and knowledge capture promotes innovation and organizational performance (Rutten, Blaas-Franken, and Martin, 2016,202)

Success factors for knowledge management can be summarized in the following points:

- Knowledge-oriented corporate culture

- Continuous learning and knowledge exchange

- Technical / organizational infrastructure

- Commitment to senior management and leadership

- $\quad$ Link to Economics or Industry Value (Mertins, Heisig, \& Vorbeck, 2004)

As for (Fernandez \& Sabherwal, 2010, 93), they categorized knowledge management processes as follows:

- Discovering knowledge: Any development of new knowledge, whether implicit or explicit, through data and information or through the incorporation of previous knowledge components, and this is done through aggregation in the event that explicit knowledge is discovered or through social interaction in the event that new implicit knowledge is discovered.

-Possessing knowledge: It means retrieving the explicit or implicit knowledge that lies inside people or that is reflected in the industrial product or organizational structures, and knowledge may be acquired from outside the organization, and this is done through the two processes (embodiment) and means the possession of the tacit knowledge, and (empowerment) It means having explicit knowledge (Laudon \& Laudon, 2012, 420).

-Application of knowledge: Using available and acquired knowledge in making decisions and performing tasks, through the routine and orientation processes, the goal and purpose of knowledge management is to apply the knowledge available to the organization. This implementation is the most prominent of its operations. This process refers to the terms of use, reuse, use, and application, which makes the organization's activities more convenient to use and more appropriate to the tasks it performs; it is a mechanism that involves assimilating knowledge and translating it into actionable operations on the ground.

-Knowledge Sharing: Through which explicit or implicit knowledge is transmitted to others effectively so that the future of knowledge can be well understood, enabling it to work in the light of it, provided that knowledge is shared, not recommendations based on it. Training sessions, informal networks, and experiences that are communicated with a supportive culture play a key role in helping managers to share important knowledge and information (Laudon \& Laudon, 2012, 420).

\subsection{Marketing Performance}

Organizations strive to achieve the goals outlined in their marketing plans. They strive to achieve this in order to raise their share in the regulatory market and achieve growth in the target market in an ongoing manner. And therefore, the organizations seek to control their performance in an ongoing manner. This control is enforced through the use of different methods. In order to increase market share and achieve growth, organizations seek to assess their strategic performance. They are also seeking to adjust their plans in a way that is consistent with the latest developments. Marketing performance can be defined as the extent to which the goals included in the company's marketing plan are met (Wheelen \& Hunger, 2008).

In light of the foregoing, it can be clear that it is important for an organization to achieve a competitive advantage compared to its competitors. It should be noted that all organizations seek to develop marketing plans and strategies in order to achieve a competitive advantage and improve their marketing performance. (Adams \& Lamont, 2003).

Beukes and van Wyk (2016:133) believes that in order to evaluate the marketing performance it is necessary to adhere to three criteria, which is the comparison with internal standards and external standards and amendments for any variation in commercial property rights. With regard to internal standards, performance measurement has become necessary for senior management in organizations responsible for strategic and operational decisions, 
and this has led to the use of criteria to compare the best performance in business and marketing or business plans in general are an internal standard of performance (Ambler \& Clark, 2001: 236). As for external standards, it is the case in which the organization compares the performance of successful organizations or competitors, regardless of how well the company's internal process has performed and its performance, it must always set a standard outside its environment against forces and competitors in order to ensure continuous improvement (Ambler \& Clark, 2001: 236).

Marketing performance measures include: the current sales volume of the product line, the market share size, the percentage of sales that are distributed through intermediaries, the level of consumer awareness of the company's advertising campaigns, the image of the organization in the mind of the consumer and intermediaries, the level of customer satisfaction and satisfaction with the organization's products, the proportion of marketing costs For total costs, failure rate for new products (Haider, 2002, 323)

Aggarwal \& Gupta (2006) showed that traditional financial metrics for marketing performance (profit, sales, cash flow) have expanded to include a range of non-financial factors (such as market share, quality, customer satisfaction, loyalty, and commercial property rights) as well as input measures (such as marketing auditing, Implementation) and Output (Marketing Auditing, Efficiency / Effectivness).

Soliman (2011: 10) defines marketing performance management as the system that measures the extent to which marketing and promotion campaigns contribute to the total sales revenue of the organization, where marketers study revenue and revenue and link it to the operational costs of marketing campaigns and indicate the nature of impact in terms of positive and negative. Merrilees et al. (2011: 370) emphasize that the idea of managing marketing performance includes the technologies, services and solutions that the organization has relied on in supporting its marketing ability, such as improving marketing programs, marketing campaigns, methods used, tools and resources.

\section{Study Hypothesis}

- There is an impact of knowledge management on improving marketing performance in small and medium enterprises in the State of Kuwait.

- There are differences in the impact of knowledge management on improving the marketing performance in small and medium enterprises in the State of Kuwait due to the owners educational qualification of small and medium projects

- There are differences in the impact of knowledge management on improving the marketing performance in small and medium enterprises in the State of Kuwait due to owners practical experience of small and medium projects

\section{Study Methodology}

This study is an analytical descriptive study to identify the impact of knowledge management on improving marketing performance in small and medium projects in the State of Kuwait, through a review of theoretical literature and previous studies related to study variables through the use of the descriptive approach and conducting the field study as part of the analytical approach.

\section{Data Collection Methods}

Primary data: It is collected through the study questionnaire, which will be prepared to achieve the goals of the study and test its hypotheses.

Secondary data: Secondary data sources will be referred to from books, references, periodicals, magazines and previous relevant studies.

\section{Population and Sampling}

The study population consisted of all the owners of small and medium enterprises in the State of Kuwait. An appropriate sample of 150 respondents was used and 124 valid questionnaires were retrieved for analysis.

\section{Analysis and Discussion}

Frequency and percentages have been computed for the sample's characteristics. 
Table 1. Sample's Distribution According to Demographic Information

\begin{tabular}{ccc}
\hline Category & Frequency & Percentage\% \\
\hline High School or less & Education & \\
Diploma & 12 & 9.7 \\
Bachelor & 42 & 33.9 \\
High studies & 60 & 48.4 \\
Total & 10 & 8.1 \\
& 124 & 100.0 \\
5years or less & Experience & \\
6-10 years & 6 & 4.8 \\
11-15 years & 14 & 11.3 \\
Above 15 years & 12 & 9.7 \\
Total & 92 & 74.2 \\
& 124 & 100.0 \\
Male & Gender & \\
Female & 92 & 74.2 \\
Total & 32 & 25.8 \\
\hline
\end{tabular}

From the table above, it is illustrated that $9.7 \%$ of the sample has High School or less, whereas $33.9 \%$ of the sample has a diploma, $48.4 \%$ of the sample has bachelor degree, and the rest have higher studies. Also, it shows that less than 5 years is $(4.8 \%)$. (6-8years) is $(\% 11.3)$, (11-15years) is $(9.7 \%)$ and above 15 years is $(74.28 \%)$ percent. Finally, it is found that the majority of the sample (74.2\%) is males and the rest is females.

Table 2. Means and Standard Deviations for the variables

\begin{tabular}{rrrc}
\hline NO. & Statement & Mean & S. Deviation \\
\hline 1. & knowledge management & 4.0161 & .63251 \\
2. & marketing performance & 4.3452 & .92106 \\
\hline
\end{tabular}

This table 2 indicates that there are positive attitudes toward the above variables because their means are above the mean of the scale 3 .

\section{Reliability Test}

A Cronbach Alpha test has been used to ascertain instrument reliability. The value has been $=0.919$ for the questionnaire. All values are accepted since they are more than $60 \%$.

\section{Hypothesis Testing}

- There is an impact of knowledge management on improving marketing performance in small and medium enterprises in the State of Kuwait. 
Table 3. Hol testing

\begin{tabular}{|c|c|c|c|c|}
\hline Model & $R$ & $R$ Square & $\begin{array}{l}\text { Adjusted } R \\
\text { Square } \\
\end{array}$ & $\begin{array}{c}\text { Std. Error of the } \\
\text { Estimate }\end{array}$ \\
\hline 1 & $.780^{\mathrm{a}}$ & .609 & .606 & .57846 \\
\hline \multicolumn{5}{|c|}{ a. Predictors: (Constant), K M } \\
\hline
\end{tabular}

\begin{tabular}{ccccccc}
\hline \multicolumn{7}{c}{ ANOVA } \\
\hline \multirow{2}{*}{1} & Model & Sum of Squares & $d f$ & Mean Square & $F$ & Sig. \\
& Regression & 63.524 & 1 & 63.524 & 189.845 & .000 \\
& Residual & 40.823 & 122 & .335 & & \\
& Total & 104.347 & 123 & & & \\
\hline
\end{tabular}

\begin{tabular}{ccccccc}
\hline \multicolumn{7}{c}{ Coefficients } \\
\hline & & \multicolumn{9}{c}{ Standardized } \\
& & \multicolumn{7}{c}{ Unstandardized Coefficients } & Coefficients & & \\
\cline { 3 - 5 } & Model & Std. Error & Beta & $t$ & Sig. \\
\hline \multirow{2}{*}{1} & (Constant) & -.218 & .335 & & -.650 & .517 \\
& K_M & 1.136 & .082 & .780 & 13.778 & .000
\end{tabular}

a. Dependent Variable: M_P

Table 3 provides results of regression analysis and ANOVA for above hypothesis. The R-value of 0.78 was obtained denoting a correlation between dependent and independent variables with the $F$ value of 189.845 at $\mathrm{P}$-value $<0.05$ confirming that there is an impact of knowledge management on improving marketing performance in small and medium enterprises in the State of Kuwait

There are differences in the impact of knowledge management on improving the marketing performance in small and medium enterprises in the State of Kuwait due to the owners' educational qualification of small and medium projects.

Table 4. Ho2 testing

\begin{tabular}{|c|c|c|c|c|c|}
\hline Source & $\begin{array}{c}\text { ype III Sum } \\
\text { Squares }\end{array}$ & $d f$ & Mean Square & $F$ & Sig. \\
\hline Corrected Model & $94.459^{\mathrm{a}}$ & 19 & 4.972 & 52.291 & .000 \\
\hline Intercept & 65.330 & 1 & 65.330 & 687.147 & .000 \\
\hline edlevel & .027 & 1 & .027 & .283 & .596 \\
\hline K_M & 70.957 & 18 & 3.942 & 41.463 & .000 \\
\hline Error & 9.888 & 104 & .095 & & \\
\hline Total & 2445.520 & 124 & & & \\
\hline Corrected Total & 104.347 & 123 & & & \\
\hline \multicolumn{6}{|c|}{ a. R Squared $=.905($ Adjusted R Squared $=.888)$} \\
\hline
\end{tabular}

Table 4 provides results of ANOVA for above hypothesis. The $\mathrm{F}$ value of 0.283 at $\mathrm{P}$-value $>0.05$ confirming that there are no differences in the impact of knowledge management on improving the marketing performance in small and medium enterprises in the State of Kuwait due to the owners' educational qualification of small and medium projects. 
- $\quad$ There are differences in the impact of knowledge management on improving the marketing performance in small and medium enterprises in the State of Kuwait due to owners' practical experience of small and medium projects

Table 5. Ho3 testing

\begin{tabular}{cccccc}
\hline \multicolumn{7}{c}{ Tests of Between-Subjects Effects } \\
\hline \multicolumn{7}{c}{ Dependent Variable: } & M_P \\
Type III Sum of & & & \\
Source & Squares & $d f$ & Mean Square & $F$ & Sig. \\
\hline Corrected Model & $94.700^{\mathrm{a}}$ & 19 & 4.984 & 53.735 & .000 \\
Intercept & 41.825 & 1 & 41.825 & 450.909 & .000 \\
exper & .268 & 1 & .268 & 2.890 & .092 \\
K_M & 91.428 & 18 & 5.079 & 54.760 & .000 \\
Error & 9.647 & 104 & .093 & & \\
Total & 2445.520 & 124 & & &
\end{tabular}

a. $\mathrm{R}$ Squared $=.908($ Adjusted R Squared $=.891)$

Table 5 provides results of ANOVA for above hypothesis. The $\mathrm{F}$ value of 2.89 at $\mathrm{P}$-value $>0.05$ confirming that there are no differences in the impact of knowledge management on improving the marketing performance in small and medium enterprises in the State of Kuwait due to owners' practical experience of small and medium projects.

\section{Discussion and Conclusion}

This study aimed to identify the impact of knowledge management on the marketing performance in small and medium projects in the State of Kuwait, and after the study was applied to a sample of 124 respondents, an effect of knowledge management has been found on the marketing performance in small and medium projects in the State of Kuwait. This reflects the importance of attention to diversifying the sources of obtaining knowledge from the environment surrounding the project in a manner that can be used to its advantage in order to improve the level of its marketing performance.

This is of course consistent with the most prominent previous studies that have highlighted the importance of knowledge management for business organizations. The study also highlighted that the opinions of the study sample on the impact of knowledge management on the marketing performance in small and medium enterprises in the State of Kuwait do not differ according to their practical experiences and scientific qualifications.

Also, it is needed for focusing on providing reports of the customer records system with immediate response, to identify changes that may occur in their tastes and desires. As well as, The Marketing Department must make sure to collect information and data about its products permanently, in order to be able to address and face any changes that may occur to its sales volumes.

\section{References}

Adams, G. L. \& Lamont, T. (2003). Knowledge Management Systems and Developing Sustainable Competitive Advantage. Journal of Knowledge Management, 7(2), 142-154.

Aggarwal, N. \& Gupta, M. (2006). Marketing Performance Measures: Current Status in Indian Companies. Decision, 33(1), 47-74

Ambler, T. \& Clark, B. H. (2001). Marketing performance measurement: evolution of research and practice. International Journal of Business Performance Measurement, 3(2), 231-244.

Beukes, C. \& van Wyk, G. (2016). An investigation of the marketing performance measurement practices in Hatfield Volkswagen group. African Journal of Business Management, 10(6), 131-139.

Fernandez, B. \& Sabherwal, I. (2010). Knowledge Management: Systems and Processes. M.E. Sharpe, Inc, Armonk, New York: Library of Congress Cataloging-in-publication data.

Haider, M. (2002). Information Systems - An Introduction to Achieving Competitive Advantage, Alexandria: University House. 
Hung, S., Chia-An Tsai, J., Lee, W. \& Y.K. Chau, P. (2015). Knowledge management implementation, business process, and market relationship outcomes: An empirical study. Information Technology \& People, 28(3), $500-528$

Laudon K.C. \& Laudon, J.P. (2012). Management Information Systems: Managing the Digital Firm (12th ed.). New Jersey: Pearson Prentice Hall, Inc., Upper Saddle Rive

Little, S. \& Ray, T. (2005). Managing Knowledge: an essential reader. 2nd edition. Sage Publications Ltd.

Martins , K., Heisig. P. \& Vorbeck . I. (2001). Knowledge Management: Best Practices in Europe. BrlinHeidelberg, Springer - Verlage

Merrilees, B., Rundle-Thiele, S. \& Lye, A. (2011). Marketing capabilities: Antecedents and implications for B2B SME performance. Industrial Marketing Management, 40(3), 368-375.

Mertins, K., Heisig, P. \& Vorbeck, J. (2004). Knowledge Management Concepts and Best Practices. Beijing, Tsinghua University Press.

Nicolas, R. (2004). Knowledge management impacts on decision making process. Journal of Knowledge Management, 8(10), 20 - 31.

Nuri, Haider (2011). The Impact of Knowledge Management Operations on Developing Distinguished Capabilities: An Empirical Study in Diyala State Company for Electrical Industries. Diyala Journal, 48, 126-160

Ologbo,A., Nor, K. \& Kwakye, E. (2015). The Influence of Knowledge Sharing on Employee Innovation Capabilities. International Journal of Human Resource Studies, 5(3), 102-110

Perera, C. \& Ranawaka, R. (2016). Analyze the Impact of Knowledge Management on Organizational Performances. Scientific Research Journal (SCIRJ), 4(11), 41-45

Rutten, W., Blaas-Franken, J. \& Martin, H. (2016). The impact of (low) trust on knowledge sharing. Journal of knowledge management, 20(2), 199-214.

Soliman, H. S. (2011). Customer relationship management and its relationship to the marketing performance. International journal of business and social science, 2(10),166-182

Waltz, E. (2003). Knowledge Management, Artech House, Boston.

Wheelen, L. \& Hunger, J. D. (2008). Strategic Management Business policy, 11th edn. New Jersey: Pearson international edition.

\section{Copyrights}

Copyright for this article is retained by the author(s), with first publication rights granted to the journal.

This is an open-access article distributed under the terms and conditions of the Creative Commons Attribution license (http://creativecommons.org/licenses/by/3.0/). 